\title{
TCF4/ $\beta$-catenin complex is directly upstream of FGF21 in mouse stomach cancer cells
}

\author{
JIHUA PEI $^{1 *}$, NA SONG $^{2 *}$, LIMIN WU $^{1}$, JINBO QI $^{2}$, SHENGLONG XIA $^{1}$, CHANGLONG XU $^{1}$, \\ BO ZHENG $^{1}$, JUN YANG ${ }^{2}$, YANYAN QIU ${ }^{2}$, HAIJUN WANG ${ }^{3}$ and YI JIANG ${ }^{1}$ \\ ${ }^{1}$ Department of Gastroenterology, The Second Affiliated Hospital of Wenzhou Medical University, \\ Wenzhou, Zhejiang 325027; Departments of ${ }^{2}$ Molecular Biology and Biochemistry, and \\ ${ }^{3}$ Pathology, Xinxiang Medical University, Xinxiang, Henan 453003, P.R. China
}

Received October 27, 2016; Accepted June 29, 2017

DOI: $10.3892 /$ etm.2017.5493

\begin{abstract}
Fibroblast growth factor 21 (FGF21) as a member of the FGFs serves a key role in glucose homeostasis and protection of the liver, heart, kidney and skin from damage as well as cancer cell development. In addition, transcription of FGF21 is sensitive to diverse damages; however, the role of the transcriptional regulator of FGF21 in cancer cells remains to be elucidated. FGFs were identified to have dominant expression in cancer cells; therefore, mouse forestomach carcinoma (MFC) cells were used in the present study, which is a mouse stomach cancer cell strain for identifying the $F G F 21$ regulators. In promoter analysis of $F G F 21$, the putative transcription factor 4 (TCF4) binding motifs $\left({ }^{\mathrm{T}} / \mathrm{A} / \mathrm{G}_{\mathrm{G}} \mathrm{AAAG}\right)$ were observed within $1.5 \mathrm{~kb}$ of the promoter region. Further chromatin immunoprecipitation and yeast-one hybrid assays identified that TCF4 directly bound to one of the two putative binding motifs observed. A co-immunoprecipitation assay identified that $\beta$-catenin interacts with TCF4 in MFC cells, and the $\beta$-catenin/TCF4 complex bound to the promoter of FGF21. In order to examine the function of TCF4 and $\beta$-catenin in transcriptional regulation of FGF21, TCF4 and $\beta$-catenin was transiently expressed in MFC cells. Reverse transcription-quantitative polymerase chain reaction results revealed that overexpression of TCF4 and $\beta$-catenin activated FGF 21 transcription. Besides, suppression of $\beta$-catenin via a specific short interfering RNA resulted in reduction
\end{abstract}

Correspondence to: Dr Yi Jiang, Department of Gastroenterology, The Second Affiliated Hospital of Wenzhou Medical University, 109 Xueyuan West Road, Wenzhou, Zhejiang 325027, P.R. China E-mail: yijiang1970@126.com

Dr Haijun Wang, Department of Pathology, Xinxiang Medical University, 601 Jinsui Road, Xinxiang, Henan 453003, P.R. China E-mail:wnavy200299@163.com

*Contributed equally

Key words: fibroblast growth factor 21, transcription factor 4, $\beta$-catenin, activation, interaction of FGF21 expression. Together these findings suggest that the $\beta$-catenin/TCF complex directly activates $F G F 21$ via promoter binding. The observations of the present study may help elucidate the regulatory mechanism of FGF21, which is a key pharmaceutical protein.

\section{Introduction}

Fibroblast growth factors (FGFs) include 23 members, which serve important roles in metabolism regulation and development (1). FGFs have been demonstrated to be associated with the processes of embryogenesis, gastrulation, somitogenesis, body plan formation, organogenesis and skin wound healing (2-7). FGF21 is a member of the FGF family that belongs to the FGF19 subfamily, and activation of the FGF receptor by FGF21 requires the co-receptor $\beta$-klotho $(8,9)$. $F G F 21$ has been reported to preferentially express in the liver (10). However, previous studies have identified that FGF21 is also highly expressed in mouse skin tissue as well as an inducible feature of $F G F 21$ by starvation, drug administration and wounding, and its diverse function in glucose homeostasis, liver and heart protection from injury or skin wound healing (11-15). Recently, FGF21 has been shown to improve hepatic insulin sensitivity by inhibiting the mammalian target of the rapamycin complex 1 (16).

Fasting-mediated induction of $F G F 21$ was regulated by the nuclear receptor peroxisome proliferator-activated receptor $\alpha(\operatorname{PPAR} \alpha)$ in the liver (17). Further studies identified that nuclear receptor retinoic acid receptor-related receptor $\alpha$ $(\mathrm{ROR} \alpha$ ) regulates $F G F 21$ in hepatocytes (18), whereas retinoic acid receptor $\beta(\mathrm{RAR} \beta)$ regulates hepatic induction of $F G F 21$ to promote fatty acid oxidation (19), indicating the complexity of transcriptional regulation of FGF21. The canonical Wnt signaling pathway is also defined as the $\mathrm{Wnt} / \beta$-catenin or the $\beta$-catenin/T-cell factor (TCF) pathway (20) that regulates diverse aspects of biological processes (21-23). The hallmark of the Wnt/ $\beta$-catenin pathway is the stabilization of cytosolic $\beta$-catenin. Under unstimulated conditions, $\beta$-catenin is constantly phosphorylated by a destruction complex consisting of glycogen synthase kinase-3 $\beta$ (GSK3 $\beta$ ) and other proteins (24); phosphorylated $\beta$-catenin is ubiquitinated by this complex and targeted for degradation by the 
proteasome $(24,25)$. Furthermore, activation of the Wnt cascade inhibits GSK $3 \beta$ activity, allowing $\beta$-catenin accumulation and subsequent relocation to the nucleus, where it associates with $\mathrm{TCF} /$ lymphoid enhancer binding factor ( $\mathrm{TCF} / \mathrm{LEF}$ ), leading to the transcription of Wnt signaling genes that are associated with cell survival, proliferation and differentiation (24). Genome wide array of TCF/LEF binding sequences analysis identified that transcription regulation complex including TCF/LEF binds to the putative cis-elements $\left(\mathrm{T} / \mathrm{A} / \mathrm{G}_{\mathrm{G}} \mathrm{AAAG}\right)$ appeared in the promoter of downstream genes (26). However, connections between TCF/LEF and FGF 21 have not yet been reported.

In the present study, the appearance of the putative TCF/LEF binding motifs in the promoter of FGF21 was observed via promoter sequence analysis. Furthermore, chromatin immunoprecipitation (ChIP) and yeast-one hybrid assays were performed to test the possibility of transcription factor 4 (TCF4) binding to the promoter of FGF21. In addition, $\beta$-catenin interaction with TCF4 and transcriptional regulation of the $\beta$-catenin/TCF4 complex to $F G F 21$ was also examined. Finally, the experiments transiently overexpressing TCF4 and $\beta$-catenin or $\beta$-catenin-specific short interfering (si) RNA were performed to test $F G F 21$ transcription levels. Together, these results indicate that the $\beta$-catenin/TCF4 complex directly regulates $F G F 21$ transcription and the present findings may help elucidate $F G F 21$ transcriptional regulation.

\section{Materials and methods}

Cell culture. The mouse forestomach carcinoma (MFC) fibroblast cell line, purchased from Bena Culture Collection (Suzhou, China; cat. no. BNCC100581), was plated at a density sufficient to create a confluent monolayer following $12 \mathrm{~h}$ of culture at $37^{\circ} \mathrm{C}$ in an incubator with $5 \% \mathrm{CO}_{2}$. Cells were cultured in Dulbecco's modified Eagle's medium (cat. no. 11965-092) containing $0.5 \%$ fetal bovine serum (cat. no. 10437-028; Thermo Fisher Scientific, Inc., Waltham, MA, USA).

Yeast-one hybrid assay. For a yeast one-hybrid assay, the 1.5-kb FGF21 was amplified from genomic DNA of MFC fibroblast cells by polymerase chain reaction (PCR) under the following conditions: Initial denaturation at $98^{\circ} \mathrm{C}$ for $30 \mathrm{sec}$, followed by 30 cycles at $98^{\circ} \mathrm{C}$ for $10 \mathrm{sec}, 65^{\circ} \mathrm{C}$ for $20 \mathrm{sec}$ and $72^{\circ} \mathrm{C}$ for $2 \mathrm{~min}$, with a final extension step at $72^{\circ} \mathrm{C}$ for $10 \mathrm{~min}$. PCR was performed using Q $5^{\circledR}$ High-Fidelity DNA Polymerase (cat. no. M0491; New England Biolabs, Inc., Ipswich, MA, USA) and the primers listed in Table I. Then, FGF21 promoter sequences were cloned into the $p H I S i$ vector (cat. no. 102239; BioVector NTCC Inc., Beijing, China), in which FGF21 promoter drives histidine synthase coding sequences. The open reading frame (ORF) sequences of TCF4 were cloned into the $p G A D 424$ vector (BioVector NTCC Inc., Beijing, China). The constructed $p G A D 424-T C F 4$ or empty vector $p G A D 424$ was transformed into the yeast one hybrid bait strain (YM4271) using a transformation solution (polyethylene glycol, lithium acetate, Tris, and EDTA; STZ; Sigma-Aldrich; Merck KGaA, Darmstadt, Germany) under the following conditions: $28^{\circ} \mathrm{C}$ for $30 \mathrm{~min}, 42^{\circ} \mathrm{C}$ for $15 \mathrm{~min}$ and $28^{\circ} \mathrm{C}$ for $5 \mathrm{~min}$. After transformation, the yeast cells were harvested at $10,000 \mathrm{x} \mathrm{g}$ for $1 \mathrm{~min}$, and the supernatant was removed. The cells were suspended in the $\mathrm{dH}_{2} \mathrm{O}$ and plated on synthetic dropout (SD)-Leu or -His media (Takara Biotechnology Co., Ltd., Dalian, China) with subsequent growth at $30^{\circ} \mathrm{C}$ for 3 days.

ChIP assay. ChIP assay was performed using a ChIP assay kit (cat no. 17-295; EMD Millipore, Billerica, MA, USA) according to the manufacturer's instructions. A total of $1 \mu \mathrm{g}$ anti-TCF4 antibody (cat. no. 2566; Cell Signaling Technology, Inc., Danvers, MA, USA) and anti- $\beta$-catenin antibody (cat. no. ab32572; Abcam, Cambridge, UK) were used for immunoprecipitation. The immunoprecipitated (IP) DNA by the antibodies were compared with the DNA precipitated without addition of antibodies using quantitative PCR (qPCR) with SYBR-Green mixture (cat. no. 4472908; Thermo Fisher Scientific, Inc.), according to the manufacturer's protocol. A reaction of ChIP-PCR was performed with an initial denaturation at $95^{\circ} \mathrm{C}$ for $3 \mathrm{~min}$, followed by 40 cycles of denaturation for $30 \mathrm{sec}$ at $95^{\circ} \mathrm{C}$, annealing for $30 \mathrm{sec}$ at $58^{\circ} \mathrm{C}$, and extension at $72^{\circ} \mathrm{C}$ for $30 \mathrm{sec}$, followed by a final extension at $72^{\circ} \mathrm{C}$ for $5 \mathrm{~min}$. GAPDH was used as a reference gene to normalize data. The primer sequences for qPCR are listed in Table I. The $2^{-\Delta \Delta C q}$ method was used for the fold change calculation (27).

Co-immunoprecipitation (Co-IP) assay. A Nuclear-Cytosolic Protein Extraction kit (Nanjing KeyGen Biotech Co., Ltd., Nanjing, China) was used for protein extraction of MFC cells. A total of $500 \mu \mathrm{g}$ (in $500 \mu \mathrm{l}$ ) extracted protein was incubated at $4^{\circ} \mathrm{C}$ with $1 \mu \mathrm{g}$ anti-TCF4 antibody (cat. no. 2566; Cell Signaling Technology, Inc.), anti- $\beta$-catenin antibody (cat. no. ab32572; Abcam), and horseradish peroxidase-conjugated anti-mouse immunoglobulin G (IgG) H\&L (ab6789; Abcam) for $1 \mathrm{~h}$. Subsequently, $20 \mu \mathrm{l}$ MagnaBind Protein A Beads (cat no. 21348; Thermo Fisher Scientific, Inc.) were added and incubated for $2 \mathrm{~h}$. Following centrifugation at 10,000 x g at $4^{\circ} \mathrm{C}$ for $5 \mathrm{~min}$, the beads were washed four times with extraction buffer containing $0.1 \%$ Triton X-100 and eluted with SDS sample buffer.

Western blot analysis. Cells were lysed in an ice-cold lysis solution containing $7 \mathrm{M}$ urea, $2 \mathrm{M}$ thiourea, 2\% 3-[(3-cholamidopropyl)dimethylammonio]-1-propanesulfonate, $40 \mathrm{mM}$ Trizma base, $40 \mathrm{mM}$ dithiothreitol and $1 \%$ protease inhibitor. Following complete lysis of the cells and centrifugation at $15,000 \mathrm{x} \mathrm{g}$ for $15 \mathrm{~min}$ at $4^{\circ} \mathrm{C}$, the total protein concentration in the supernatant was measured using a Bradford protein assay kit (Bio-Rad Laboratories, Inc., Richmond, CA, USA). The proteins (40 $\mu \mathrm{g} /$ lane) were separated on $12 \%$ SDS-PAGE and electrotransferred onto Immobilon-P transfer membranes (EMD Millipore). The membranes were incubated in TBS containing 5\% skimmed milk and $0.05 \%$ Tween-20 for $1 \mathrm{~h}$ and blotted with primary antibodies at $4^{\circ} \mathrm{C}$ overnight. Anti-TCF4 (1:1,000; cat. no. 2566; Cell Signaling Technology, Inc.), anti- $\beta$-catenin (1:2,000; cat. no. ab32572; Abcam) and anti-GAPDH (1:2,000; cat. no. ab8245; Abcam) antibodies were used as the primary antibodies. GAPDH was used as the internal control. The membranes were incubated for $1 \mathrm{~h}$ at $37^{\circ} \mathrm{C}$ with an anti-mouse or anti-rabbit horseradish peroxidase-linked secondary antibody (1:2,000; cat. nos. 7076 and 7074, Cell Signaling Technology, Inc.), and the signal 
Table I. Primer sequences.

\begin{tabular}{|c|c|}
\hline Primer & Sequences $\left(5^{\prime}-3^{\prime}\right)$ \\
\hline FGF21 & $\begin{array}{l}\text { F: GATGACGACCAAGACACTG } \\
\text { R: CGGCCCTGTAAAGGCTCT }\end{array}$ \\
\hline TCF4 & $\begin{array}{l}\text { F: AGAGCGACAAGCCCCAGAC } \\
\text { R: ATTCGCTGCGTCTCCCATC }\end{array}$ \\
\hline$\beta$-catenin & $\begin{array}{l}\text { F: TCGCCAGGATGATCCCAGC } \\
\text { R: GCCCATCCATGAGGTCCTG }\end{array}$ \\
\hline GAPDH & $\begin{array}{l}\text { F: GCCAAGGTCATCCATGACAACT } \\
\text { R: GAGGGGCCATCCACAGTCTT }\end{array}$ \\
\hline pFGF21 & $\begin{array}{l}\text { F: GAATTCCAGAGTTCCAGGGCCA } \\
\text { CATCA } \\
\text { R: GAGCTCCAGGGCTGCGCTCCGTT } \\
\text { CGGGAG }\end{array}$ \\
\hline FGF21 F1 & $\begin{array}{l}\text { F: CTAAGCAGGGGTTGGTGAGG } \\
\text { R: GCGTGTCTGAGGCTTTCTTTC }\end{array}$ \\
\hline FGF21 F2 & $\begin{array}{l}\text { F: ACACCAGCTCAGTTGCTTACAC } \\
\text { ACTGAAGTCTACACTCCTGGGTCT }\end{array}$ \\
\hline$\beta$-catenin ORF & $\begin{array}{l}\text { F: AAGCTTATGGCTACTCAAGCTGACC } \\
\text { TGATG } \\
\text { R:CTCGAGTTACAGGTCAGTATCAAAC } \\
\text { CAGGC }\end{array}$ \\
\hline TCF4 ORF & $\begin{array}{l}\text { F: AAGCTTATGCATCACCAACAGCGA } \\
\text { ATG } \\
\text { R: CTCGAGTCACATCTGTCCCATGTGA } \\
\text { TTC }\end{array}$ \\
\hline
\end{tabular}

FGF21, fibroblast growth factor 21; F, forward; R, reverse; TCF4, transcription factor 4; ORF, open reading frame.

was visualized using an electrochemiluminescence kit (GE Healthcare, Chicago, IL, USA).

Total RNA extraction, cDNA synthesis and reverse transcription-qPCR (RT-qPCR). In total, $2 \mu \mathrm{g}$ total RNA, extracted with RNeasy Mini kit (cat. no. 74104; Qiagen China Co., Ltd., Shanghai, China) from MFC cells, was reverse-transcribed using a GoScript reverse transcription kit (Promega Corporation, Madison, WI, USA) following the manufacturer's instructions. RT-qPCR was performed with SYBR Green mixture (cat. no. 4472908; Thermo Fisher Scientific, Inc.), and gene expression was quantified as described previously (27). GAPDH was used as an internal control. The sequences of primers used in RT-qPCR are listed in Table I.

Overexpression and RNA interference. ORF regions of TCF4 (NM_013685.2, NCBI) and $\beta$-catenin (NM_001165902.1, $\mathrm{NCBI}$ ) were amplified from cDNA of MFC cells by the gene specific primers with Q5 ${ }^{\circledR}$ High-Fidelity DNA Polymerase (cat. no. M0491; New England Biolabs, Inc.) and cloned into the pcDNA3.1 (+) (cat. no. V79020; Thermo Fisher Scientific, Inc.) expression vector to contract TCF4 overexpression and $\beta$-catenin overexpressed plasmids. The primers used for
TCF4 and $\beta$-catenin are listed in Table I. siRNA for $\beta$-catenin (ON-TARGET plus SMART pool, L-004018) and negative control siRNA (ON-TARGETplus si CONTROL non-targeting pool, D-001810) were purchased from Dharmacon RNA Technologies (Chicago, IL, USA). The MFC cells were seeded $12 \mathrm{~h}$ prior to transfection at $37^{\circ} \mathrm{C}$ with $5 \% \mathrm{CO}_{2}$ and reached a density of $30-50 \%$ confluence at the time of transfection. Subsequently, $30 \mathrm{nM}$ siRNA duplex and $2 \mu \mathrm{g}$ TCF4 overexpression or $\beta$-catenin overexpression plasmids were transfected on day 0 using Lipofectamine 2000 (Invitrogen; Thermo Fisher Scientific, Inc.) and Opti-MEM I Reduced Serum Medium (Gibco; Thermo Fisher Scientific, Inc.) according to the manufacturer's instructions. On day 1 ( $24 \mathrm{~h}$ after transfection), the cells were confluent and the overexpression or siRNA solutions were exchanged with full growth medium. These transfected cells were subsequently used for RT-qPCR (as described above), for which the density reached $80-90 \%$ confluence at the time of harvest for RNA preparation on day 3 ( $72 \mathrm{~h}$ after transfection).

Statistical analysis. Data are presented as the mean \pm standard error of the mean. Each experiment was performed in triplicate. Statistical calculations were performed with Prism 5 (GraphPad Software, Inc., San Diego, CA, USA). Data were analyzed using the Student's t-test for two groups and one-way analysis of variance followed by Tukey's test for more than two groups. $\mathrm{P}<0.05$ was considered to indicate a statistically significant difference.

\section{Results}

TCF4 directly activates FGF21 transcription. FGF21 promoter sequences analysis demonstrated that two putative TCF/LEF binding motifs (AGAAAG) (26) appeared within $1.5 \mathrm{~kb}$ of the promoter. The two putative binding motifs are located 1,163 and 876 bp upstream of the start codon, respectively (Fig. 1A). In order to examine whether TCF4 directly binds to the putative motifs, ChIP assays were performed using the TCF4 antibody and the precipitation without antibody as the control. FGF21 exhibited a higher expression level in the MFC cells (data not shown); therefore, the MFC cells were used in the experiments $(14,15)$. The IP DNA fragments were amplified by two primer pairs, which spanned the F1 and F2 regions in the FGF21 promoter (Fig. 1B). The ChIP-PCR data was normalized to input DNA and the results revealed that TCF4 bound to the $\mathrm{F} 1$ but not $\mathrm{F} 2$ region in the promoter of the FGF21 gene (Fig. 1B). To further verify the ChIP results, a yeast-one hybrid assay was performed by co-expressing activation domain (AD)-TCF4 and $p F G F 21$-His or $m p F G F 21$-His (Fig. 1C). The results indicate that AD-TCF4 co-expressing pFGF21-His were able to grow in SD media missing histidine, whereas the empty vector transforming or AD-TCF4 co-expressing $m p F G F 21$-His cells failed to grow (Fig. 1D). These data indicated that TCF4 activates the FGF21 promoter in yeast.

$\beta$-catenin interacts with TCF4 and $\beta$-catenin/TCF4 complex binds to the promoter of FGF21. After $\beta$-catenin accumulates in the nucleus, it interacts with TCF/LEF, and activates the transcription of Wnt signaling genes (24). To test whether 
A

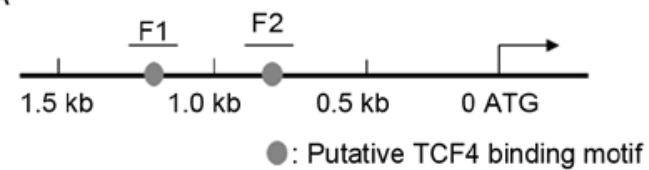

B

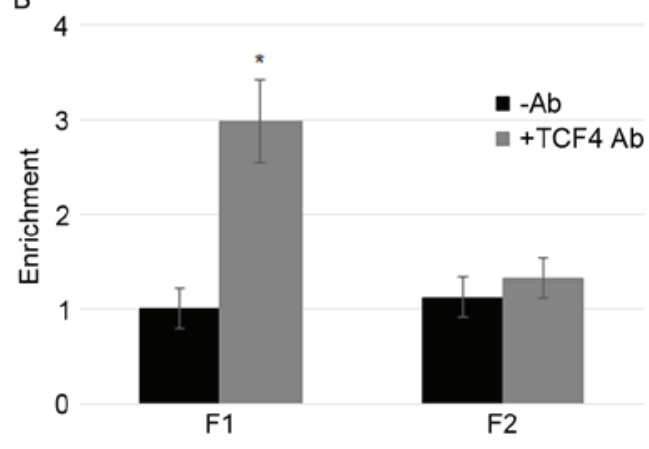

D

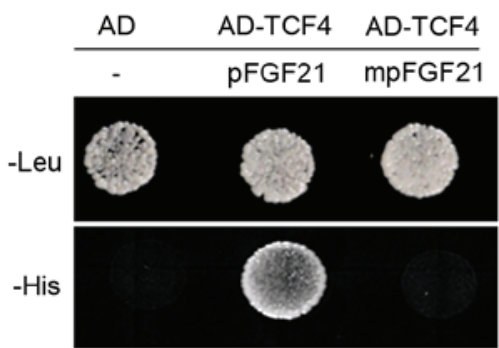

Figure 1. TCF4 bound directly to the promoter of FGF21. (A) The schematic diagram indicates the locations of the putative TCF binding motifs, F1 and F2 (gray circles), within the $1.5 \mathrm{~kb} F G F 21$ promoter. (B) A ChIP assay was performed by amplifying IP DNA to detect the F1 and F2 regions in the FGF21 promoter; relative ratios of IP DNA to input DNA was determined by ChIP-PCR, and input DNA was used to normalize the data. Data are presented as the mean \pm standard error ( $\mathrm{n}=3)$; "P<0.05 vs. $-\mathrm{Ab}$. (C) A $1.5 \mathrm{~kb}$ sequence of the $F G F 21$ promoter with or without mutations at the TCF4 binding motif was cloned into the $p H I S i$ vector in which His was a reporter gene. The gray circle indicates the TCF4 binding motif and ' $\mathrm{X}$ ' indicates mutation of the TCF4 binding sequences. (D) A yeast one-hybrid assay was performed to analyze the activation of TCF4 on the FGF21 promoter. Yeast cells harboring either the AD vector without promoter or AD-TCF4 together with $p F G F 21$-His or $m p F G F 21$-His were grown on synthetic dropout media lacking Leu or His. TCF4, transcription factor 4; FGF21, fibroblast growth factor 21; ChIP, chromatin immunoprecipitation; IP, immunoprecipitated; PCR, polymerase chain reaction; Ab, antibody; $-\mathrm{Ab}$, without antibody; $\mathrm{AD}$, activation domain.
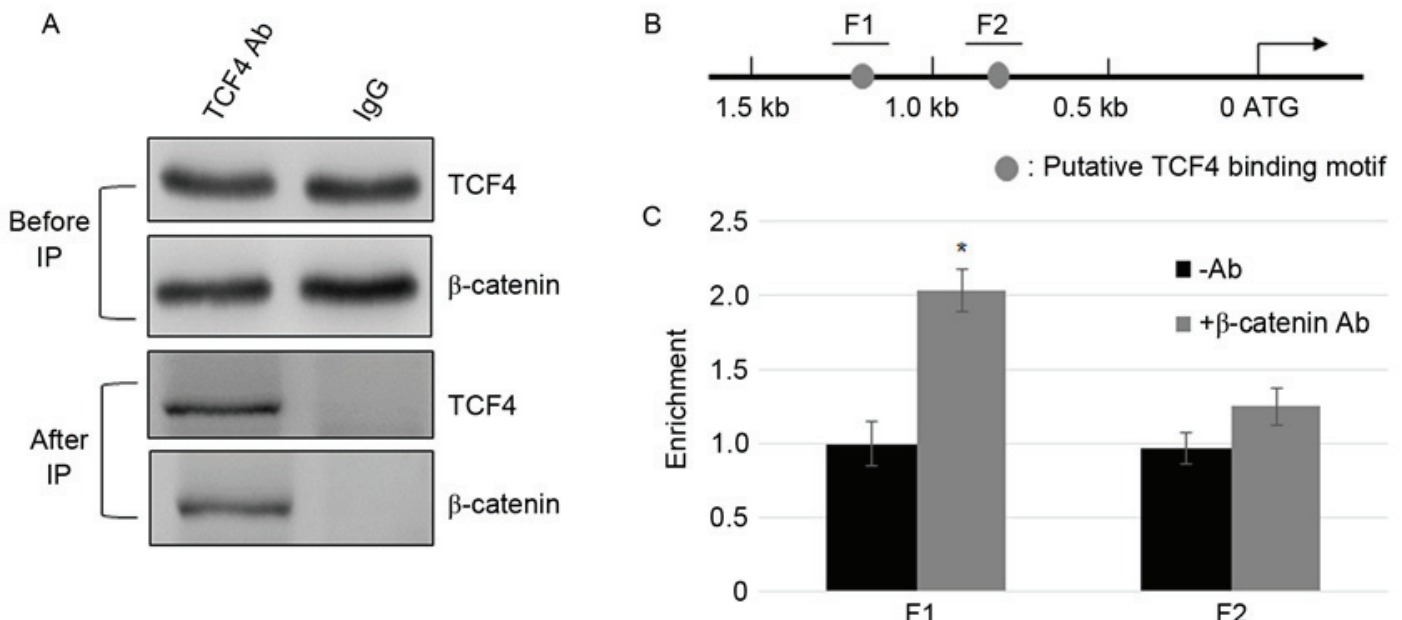

Figure 2. $\beta$-catenin physically interacts with TCF4 and binds to the promoter of FGF21. (A) Mouse forestomach carcinoma cell lysate was incubated with TCF4 Ab or immunoglobin and subjected to IP. The TCF4 and $\beta$-catenin levels were evaluated prior to and following IP by western blot analysis. GAPDH was used as an internal control. (B) The schematic diagram indicates the locations of the putative TCF binding motifs (gray circles) within the $1.5 \mathrm{~kb} F G F 21$ promoter. F1 and F2 indicate regions amplified in the ChIP-PCR analysis. (C) A ChIP assay was performed by amplifying IP DNA to detect the F1 and F2 regions in the FGF21 promoter; relative ratios of IP DNA to input DNA were determined by ChIP-PCR; input DNA was used to normalize the data. Data are presented as the mean \pm standard error of the mean $(n=3)$. ${ }^{*} \mathrm{P}<0.05 \mathrm{vs}$. $\mathrm{Ab}$. TCF4, transcription factor 4; FGF21, fibroblast growth factor 21; Ab, antibody; IP, immunoprecipitation; IgG, immunoglobulin G; ChIP, chromatin immunoprecipitation; PCR, polymerase chain reaction; -Ab, without antibody.

TCF4 and $\beta$-catenin interact in MFC cells, Co-IP assay was performed. The cell lysate was incubated with TCF4 or IgG antibodies, and $\beta$-catenin and TCF4 were detected using $\beta$-catenin and TCF4 antibodies prior to and following immunoprecipitation (Fig. 2A). GAPDH levels in IgG and TCF4 incubated samples were similar (Fig. 2A). The results indicate that $\beta$-catenin and TCF4 physically interact with the MFC cells. To further test the binding of the $\beta$-catenin complex to the promoter of FGF21, ChIP assays were performed using $\beta$-catenin. ChIP-PCR results indicate that similar to the TCF4, 
A

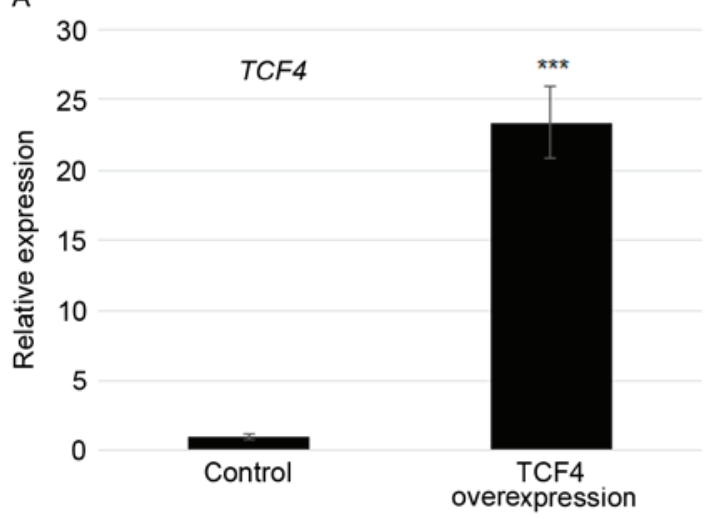

B

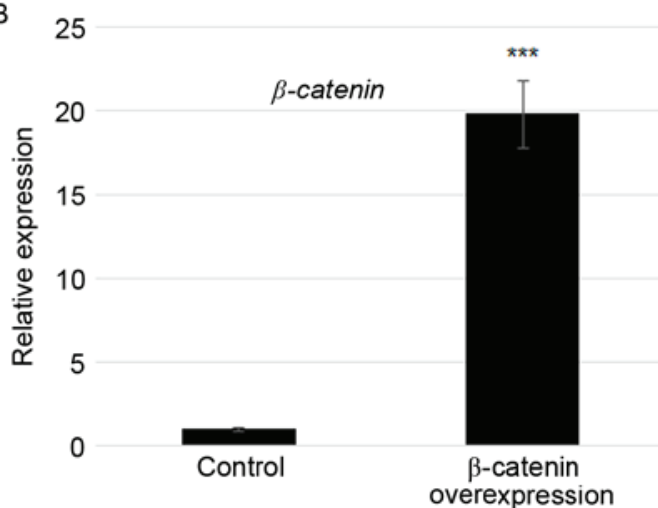

C

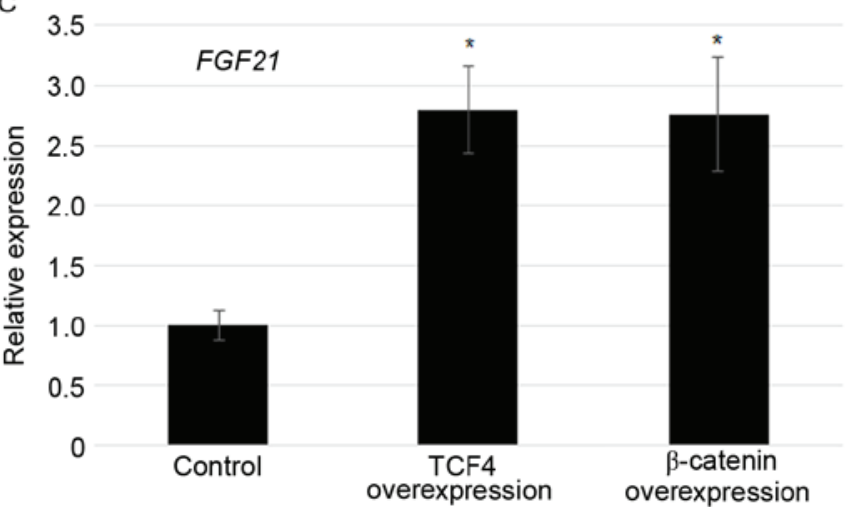

Figure 3. Overexpression of TCF4 and $\beta$-catenin activates FGF21. (A) Full length open reading frame of TCF4 and $\beta$-catenin were transiently expressed with Lipofectamine 2000 and the transcription levels of (A) TCF4 and (B) $\beta$-catenin were monitored in non-transformed (control) and transformed cells via RT-qPCR. (C) RT-qPCR was performed to examine the level of $F G F 21$ in non-transformed (control) and TCF4 or $\beta$-catenin transformed cells. GAPDH was used as an internal control. Data are presented as the mean \pm standard error of the mean $(n=3)$. ${ }^{*} \mathrm{P}<0.05$ and ${ }^{* * * *} \mathrm{P}<0.001$ vs. control. TCF4, transcription factor 4; RT-qPCR, reverse transcription-quantitative polymerase chain reaction; FGF21, fibroblast growth factor 21.

$\beta$-catenin IP DNA was enriched in the F1 region but not in the $\mathrm{F} 2$ region (Fig. 2B and $\mathrm{C}$ ).

Overexpression of TCF4 and $\beta$-catenin activated FGF21 transcription. As TCF4 and $\beta$-catenin bound to the $\mathrm{F} 1$ region of the FGF 21 promoter, effects of TCF4 and $\beta$-catenin on FGF21 expression were tested. TCF4 and $\beta$-catenin modulated transcription of $F G F 21$ was confirmed by plasmid (pcDNA3.1-TCF4 or pcDNA3.1- $\beta$-catenin)-mediated transfection experiments using Lipofectamine 2000. At $24 \mathrm{~h}$ following transfection, TCF4 was $\sim 22$-fold and $\beta$-catenin was $\sim 20$-fold higher in the TCF4 overexpression and $\beta$-catenin overexpressed cells compared with the control in which empty vector was transformed (Fig. 3A and B). Furthermore, FGF21 expression levels were monitored by RT-qPCR. The results revealed that the FGF21 transcript was 2.7 and 2.6 fold higher in TCF4 overexpression and $\beta$-catenin overexpressed cells compared with the control, respectively (Fig. 3C).

Suppression of $\beta$-catenin reduced FGF21 levels. As overexpression of $\beta$-catenin induced FGF21 expression, FGF 21 levels in the $\beta$-catenin knockdown MFC cells was analyzed further. RT-qPCR results indicated that two independent transfection of $\beta$-catenin specific siRNAs significantly reduced the expression of $\beta$-catenin ( $70-80 \%$; Fig. $4 \mathrm{~A})$. In
A

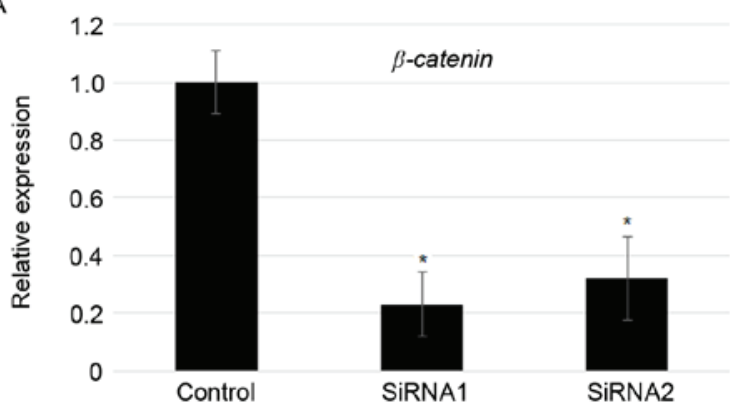

B

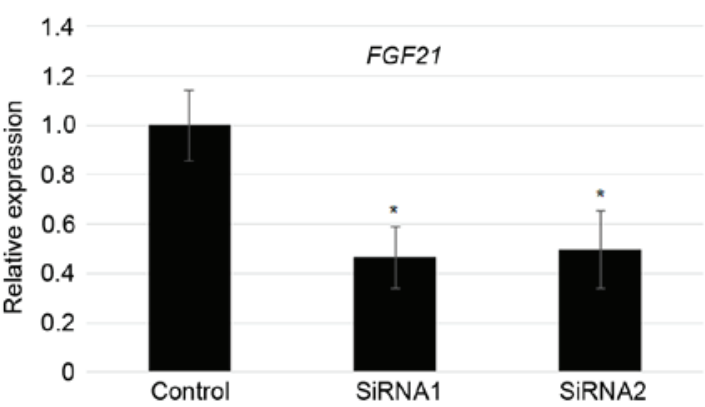

Figure 4. Suppression of $\beta$-catenin reduces the transcription of FGF21. (A) $\beta$-catenin and (B) FGF21 transcript levels were analyzed in control (scrambled) siRNA- and $\beta$-catenin siRNA (Si $\beta$-catenin)-transfected cells. GAPDH was used as an internal control. Data are presented as the mean \pm standard error of the mean $(n=3)$. ${ }^{*} \mathrm{P}<0.05$ vs. control. FGF21, fibroblast growth factor 21; siRNA, short interfering RNA. 
addition, siRNA-mediated knockdown of $\beta$-catenin largely contributed to the reduction in the expression of FGF21 ( 50\%; Fig. 4B).

\section{Discussion}

FGF21 is sensitive to diverse physiological changes (e.g., fasting and injury) and serves an important role in development and metabolism, including glucose metabolism (11-15). Transcription of FGF21 was previously identified under the control of PPAR $\alpha$ (17), ROR $\alpha$ (18), and RAR $\beta$ in hepatocytes (19). In addition, FGF21 transcription was also induced by feeding or cold treatment in brown adipose tissue $(28,29)$, indicating the complicated regulation of FGF21 transcription. To elucidate transcriptional regulation, the promoter of $F G F 21$ was investigated for identifying cis-element information. The putative TCF/LEF binding motifs (26) were observed within $1.5 \mathrm{~kb}$ of its promoter region. Furthermore, ChIP and yeast-one hybrid assays confirmed that TCF4 directly bound to one of the two putative TCF/LEF motifs in the FGF21 promoter.

TCF and $\beta$-catenin are the master transcriptional regulators of the Wnt signaling pathway, and translocation of $\beta$-catenin from the cytosol to the nucleus resulted in formation of a TCF complex, including TCF and $\beta$-catenin (24). Furthermore, the complex activates a large number of downstream genes via binding to the specific sequences in their promoters (26). To further identify the possibility that TCF $4 / \beta$-catenin complex-mediated regulation of FGF21 transcription, Co-IP and ChIP assays were performed. Co-IP results indicated that TCF4 and $\beta$-catenin interact in MFC cells. Furthermore, ChIP assay data revealed that $\beta$-catenin is associated with the FGF21 transcriptional regulator complex that may function together with TCF4. Overexpression of TCF4 or $\beta$-catenin in MFC induced $F G F 21$ transcription, whereas suppression of $\beta$-catenin via a specific siRNA repressed the $F G F 21$ level. These results indicated that TCF4 and $\beta$-catenin activates FGF21 by binding to the $\mathrm{F} 1$ region of its promoter.

Previous reports identified that $\mathrm{Wnt} / \beta$-catenin acts upstream of $F G F 2$ in lung tissues to regulate proximal-distal patterning (30). However, no direct connection between $\beta$-catenin and FGF gene was observed. In the present study, TCF $/ \beta$-catenin was identified to directly regulate $F G F 21$ in a mouse embryonic fibroblast cell line, MFC, and further experiments are indeed required to examine whether TCF4/ $\beta$-catenin mutant mice exhibit a similar phenomenon as that presented in FGF21 mutants, including glucose metabolism abnormality and heart dysfunction. However, the observations of the present study have improved the understanding of FGF21 regulation as direct connections were observed between Wnt and FGF signaling.

\section{Acknowledgements}

The present study was funded by Wenzhou Medical University (grant no. 025gt8972). This work was also supported by the Doctoral Scientific Research Foundation of Xingxiang Medical University (grant no. XYBSKYZZ201512\&201513) and grants from The Education Department of Henan Province (grant nos. 201610472040, 172102310584). The vectors and yeast strain used in the yeast two hybrid assay were kindly donated by the Yuan lab at Wenzhou Medical University.

\section{References}

1. Mohammadi M, Olsen SK and Ibrahimi OA: Structural basis for fibroblast growth factor receptor activation. CytokineGrowth Factor Rev 16: 107-137, 2005.

2. Feldman B, Poueymirou W, Papaioannou VE, DeChiara TM and Goldfarb M: Requirement of FGF-4 for postimplantation mouse development. Science 267: 246-249.1995.

3. Dubrulle J and Pourquié O: fgf 8 mRNA decay establishes a gradient that couples axial elongation to patterning in the vertebrate embryo. Nature 427: 419-422, 2004.

4. Sun X, Meyers EN, Lewandoski M and Martin GR: Targeted disruption of Fgf8 causes failure of cell migration in the gastrulating mouse embryo. Genes Dev 13: 1834-1846, 1999.

5. Martin GR: The roles of FGFs in the early development of vertebrate limbs. Genes Dev 12: 1571-1586, 1998.

6. Goldfarb M: Functions of fibroblast growth factors in vertebrate development. Cytokine Growth Factor Rev 7: 311-325, 1996.

7. Kanazawa S, Fujiwara T, Matsuzaki S, Shingaki K, Taniguchi M, Miyata S, Tohyama M, Sakai Y, Yano K, Hosokawa K and Kubo T: bFGF regulates PI3-kinase-Rac1-JNK pathway and promotes fibroblast migration in wound healing. PloS One 5: e12228, 2010.

8. Yie J, Wang W, Deng L, Tam LT, Stevens J, Chen MM, Li Y, Xu J, Lindberg R, Hecht R, et al: Understanding the physical interactions in the FGF21/FGFR/beta-Klotho complex: Structural requirements and implications in FGF21 signaling. Chem Biol Drug Des 79: 398-410, 2012.

9. Belov AA and Mohammadi M: Molecular mechanisms of fibroblast growth factor signaling in physiology and pathology. Cold Spring Harb Perspect Biol 5: a015958, 2013.

10. Nishimura T, Nakatake Y, Konishi M and Itoh N: Identification of a novel FGF, FGF-21, preferentially expressed in the liver. Biochim Biophys Acta 1492: 203-206, 2000.

11. Liang Q, Zhong L, Zhang J, Wang Y, Bornstein SR, Triggle CR, Ding H, Lam KS and Xu A: FGF21 maintains glucose homeostasis by mediating the cross talk between liver and brain during prolonged fasting. Diabetes 63: 4064-4075, 2014.

12. Lin Z, Tian H, Lam KS, Lin S, Hoo RC, Konishi M, Itoh N, Wang Y, Bornstein SR, Xu A and Li X: Adiponectin mediates the metabolic effects of FGF21 on glucose homeostasis and insulin sensitivity in mice. Cell Metab 17: 779-789, 2013.

13. Lin Z, Wu F, Lin S, Pan X, Jin L, Lu T, Shi L, Wang Y, Xu A and Li X: Adiponectin protects against acetaminophen-induced mitochondrial dysfunction and acute liver injury by promoting autophagy in mice. J Hepatol 61: 825-831, 2014.

14. Song Y, Ding J, Jin R, Jung J, Li S, Yang J, Wang A and Li Z: Expression and purification of FGF21 in Pichia pastoris and its effect on fibroblast-cell migration. Mol Med Rep 13: 3619-3626, 2016.

15. Song YH, Zhu YT, Ding J, Zhou FY, Xue JX, Jung JH, Li ZJ and Gao WY: Distribution of fibroblast growth factors and their roles in skin fibroblast cell migration. Mol Med Rep 14: 3336-3342, 2016.

16. Gong Q, Hu Z, Zhang F, Cui A, Chen X, Jiang H, Gao J, Chen X, Han Y, Liang Q, et al: Fibroblast growth factor 21 improves hepatic insulin sensitivity by inhibiting mammalian target of rapamycin complex 1 in mice. Hepatology 64: 425-438, 2016.

17. Inagaki T, Dutchak P,Zhao G, Ding X, Gautron L, Parameswara V, Li Y, Goetz R, Mohammadi M, Esser V, et al: Endocrine regulation of the fasting response by PPARalpha-mediated induction of fibroblast growth factor 21. Cell Metab 5: 415-425, 2007.

18. Wang Y, Solt LA and Burris TP: Regulation of FGF21 expression and secretion by retinoic acid receptor-related orphan receptor alpha. J Biol Chem 285: 15668-15673, 2010.

19. Li Y, Wong K, Walsh K, Gao B and Zang M: Retinoic acid receptor $\beta$ stimulates hepatic induction of fibroblast growth factor 21 to promote fatty acid oxidation and control whole-body energy homeostasis in mice. J Biol Chem 288: 10490-10504, 2013.

20. Shtutman M, Zhurinsky J, Simcha I, Albanese C, D'Amico M, Pestell R and Ben-Ze'ev A: The cyclin D1 gene is a target of the beta-catenin/LEF-1 pathway. Proc Natl Acad Sci USA 96: 5522-5527, 1999. 
21. 21. Moon RT, Kohn AD, De Ferrari GV and Kaykas A: WNT and $\beta$-catenin signalling: Diseases and therapies. Nat Rev Genet 5: 691-701, 2004.

22. Clevers H: Wnt/beta-catenin signaling in development and disease. Cell 127: 469-480, 2006.

23. Brack AS, Conboy MJ, Roy S, Lee M, Kuo CJ, Keller C and Rando TA: Increased Wnt signaling during aging alters muscle stem cell fate and increases fibrosis. Science 317: 807-810, 2007.

24. Gordon MD and Nusse R: Wnt signaling: Multiple pathways, multiple receptors, and multiple transcription factors. J Biol Chem 281: 22429-22433, 2006.

25. Aberle H, Bauer A, Stappert J, Kispert A and Kemler R: beta-catenin is a target for the ubiquitin-proteasome pathway. EMBO J 16: 3797-3804, 1997.

26. Schuijers J, Mokry M, Hatzis P, Cuppen E and Clevers H Wnt-induced transcriptional activation is exclusively mediated by TCF/LEF. EMBO J 33: 146-156, 2014.
27. Livak KJ and Schmittgen TD: Analysis of relative gene expression data using real-tie quantitative PCR and the 2(-Delta Delta C(T)) method. Methods 25: 402-408, 2001.

28. Dutchak PA, Katafuchi T, Bookout AL, Choi JH, Yu RT, Mangelsdorf DJ and Kliewer SA: Fibroblast growth factor-21 regulates PPAR $\gamma$ activity and the antidiabetic actions of thiazolidinediones. Cell 148: 556-567, 2012.

29. Fisher FM, Kleiner S, Douris N, Fox EC, Mepani RJ, Verdeguer F, Wu J, Kharitonenkov A, Flier JS, Maratos-Flier E and Spiegelman BM: FGF21 regulates PGC-1 $\alpha$ and browning of white adipose tissues in adaptive thermogenesis. Genes Dev 26: 271-281, 2012.

30. Shu W, Guttentag S, Wang Z, Andl T, Ballard P, Lu MM, Piccolo S, Birchmeier W, Whitsett JA, Millar SE and Morrisey EE: $\mathrm{Wnt} /$ beta-catenin signaling acts upstream of $\mathrm{N}$-myc, BMP4, and FGF signaling to regulate proximal-distal patterning in the lung. Dev Biol 283: 226-239, 2005. 